\title{
A randomized, placebo-controlled double-blinded comparative clinical study of five over-the- counter non-pharmacological topical analgesics for myofascial pain: single session findings
}

Daniel Avrahami ${ }^{1,3^{*}}$, Amanda Hammond ${ }^{1,4}$, Ceara Higgins ${ }^{1,5}$ and Howard Vernon ${ }^{2}$

\begin{abstract}
Objectives: To investigate the effects of topical agents for the treatment of Myofascial Pain Syndrome (MPS) and Myofascial Trigger Point (MTRP).

Methods: Subjects with an identifiable trigger point in the trapezius muscle, age 18-80 were recruited for a singlesession randomized, placebo-blinded clinical study. Baseline measurements of trapezius muscle pressure pain threshold (PPT: by pressure algometer) along with right and left cervical lateral flexion (rangiometer) were obtained by a blinded examiner. An assessor blinded to the outcomes assessments applied one of 6 topical formulations which had been placed in identical plastic containers. Five of these topicals were proposed active formulations; the control group was given a non-active formulation (PLA). Five minutes after the application of the formula the outcome measures were re-tested. Data were analyzed with a 5-way ANOVA and Holms-adjusted t-tests with an alpha level of 0.05 .
\end{abstract}

Results: 120 subjects were entered into the study (63 females; ages 16-82); 20 subjects randomly allocated into each group. The pre- and post-treatment results for pressure threshold did show significant intra-group increases for the BenGay Ultra Strength Muscle Pain Ointment (BG), the Professional Therapy MuscleCare Roll-on (PTMC roll-on) and Motion Medicine Cream (MM) with an increased threshold of $0.5 \mathrm{~kg} / \mathrm{cm}^{2}(+/-0.15), 0.72 \mathrm{~kg} / \mathrm{cm}^{2}(+/-0.17)$ and $0.47 \mathrm{Kg} / \mathrm{cm}^{2}$ (+/-0.19) respectively. With respect to the inter-group comparisons, PTMC roll-on showed significant increases in pressure threshold compared with Placebo (PLA) $(p=0.002)$ and lcy Hot Extra Strength Cream $(I H)(p=0.006)$. In addition, BG demonstrated significant increases in pressure threshold compared with PLA $(p=0.0003)$.

Conclusions: With regards to pressure threshold, PTMC roll-on, BG and MM showed significant increases in pain threshold tolerance after a short-term application on a trigger points located in the trapezius muscle. PTMC roll-on and BG were both shown to be superior vs placebo while PTMC was also shown to be superior to $\mathrm{IH}$ in patients with trigger points located in the trapezius muscle on a single application.

CMCC Research Ethics Board Approval \# 1012X01, 2011

\section{Introduction}

Myofascial Pain Syndrome (MPS) is exceedingly common in Western society [1-3]. Vernon and Schneider note that MPS is thought to be the leading diagnosis among pain management specialists $[4,5]$ and the leading diagnosis in pain patients reporting to general

\footnotetext{
* Correspondence: dr.danavrahami@gmail.com

${ }^{1}$ Toronto, ON, Canada

Full list of author information is available at the end of the article
}

practitioners $[4,6]$. MPS can be viewed as a regional pain syndrome such as, neck, low back and upper quadrant pain syndromes. MPS can also be found focally in discrete painful sites known as Myofascial Trigger Point (MTrP). Locations of MTrP's have been characterized on clinical grounds throughout the musculoskeletal system, starting with the seminal work of Travell and Simons [6,7]. MTrP's have been described as active (clinically active with pain referral upon palpation) or 
latent (not clinically active, but tender on manual palpation) [7-9]. The presence of associated features such as "local twitch sign" and palpable taut bands is thought to confirm the presence of an active MTrP, while latent TP's may not present with the classic features.

Numerous treatments are currently available for MPS and MTrP's. Several systematic reviews have recently been published on a variety of treatments [4,10-14], including pharmacologic agents, physical agents, complementary and alternative therapies. One commonly used therapy is the application of topical agents to relieve pain [15-17]. These agents can be classified as pharmacologic or non-pharmacologic. The former category includes non-steroidal anti-inflammatory agents (such as ketaprofen), opioid agents, classical analgesic agents (such as lidocaine), novel analgesic agents such as capsaicin and rubefascient agents (containing salicylates or nicotinamides) [15-17]. Non-pharmacologic agents generally fall into the complementary and alternative medicine (CAM) category for MPS and MTrP treatments. They may contain putative analgesic agents or counterirritant agents and they may exert cold, hot or neutral effects.

Several studies have investigated the effect of such topicals in the treatment of osteoarthritis, particularly of the knee $[18,19]$. However, there appears to be a lack of studies investigating the effects of topical agents for the treatment of MPS or MTrP. A randomized, placeboblinded clinical trial of non-pharmacological topical analgesics was conducted comparing leading national and professional brands in the treatment of a myofascial trigger point.

\section{Materials and methods \\ Subjects}

Subjects were selected from consecutive clinical presentations of patients for treatment in a multidisciplinary health clinic. Subjects aged 18-80, male or female, with or without neck pain were included. Subjects were excluded for the following reasons: acute pain presentation preventing comfortable participation and absence of a palpable tender spot in the right upper trapezius region. Subjects were informed of the nature of the experiment and consented to participate. This protocol was approved by the Research Ethics Board of the Canadian Memorial Chiropractic College.

\section{Randomization}

A random number sequence was generated by an independent party and kept in the care of the clinic administrator until required for subject allocation. The randomization schedule was concealed from all other study staff prior to selection and prior to group allocation.

\section{Outcome measures}

Pre- and post-intervention measures consisted of 1) tenderness at an MTrP in the upper trapezius and, 2) right and left cervical spine lateral flexion. Tenderness was measured using a manual pressure algometer and was reported in $\mathrm{kg} / \mathrm{cm}^{2}$ [20]. Once identified by palpation and marked on the skin, the MTrP was subjected to vertical pressure with the pressure algometer at the rate of $1 \mathrm{~kg} / \mathrm{cm}^{2}$ per second. The subject was instructed to indicate verbally when the first instance of tenderness was felt. A single trial was used. Right and left cervical spine lateral flexions were measured using a cervical rangiometer [21] and were reported in degrees. A single trial was used. Both measures have proven reliable and valid in the assessment of MTrP's [9,21-27]. Following the intervention, subjects were asked to rate their level of satisfaction on a verbal satisfaction scale $(\mathrm{P}=$ poor, $\mathrm{F}$ = fair, $\mathrm{G}=$ good, $\mathrm{E}=$ excellent).

\section{Interventions}

Six topical products were tested: three were ointments, two were roll-on gels and one a non-medicinal placebo cream (PLA) which served as the control. The comparative topicals were Professional Therapy MuscleCare Roll-on ${ }^{\mathrm{a}}$ (PTMC roll-on), Motion Medicine cream $^{\mathrm{b}}$ (MM cream), Bengay Ultra Strength Muscle Pain ointment $^{\mathrm{c}}$ (BG), Icy Hot Extra Strength Cream ${ }^{\mathrm{d}}(\mathrm{IH})$, and Biofreeze roll-on gel $^{\mathrm{e}}(\mathrm{BF})$. All of these products were placed in identical 0.5 ounce white plastic screw top containers or 3 ounce generic white roll-on bottles. Only a coded letter was applied as a label. The master code for these products was kept with the clinic administrator and was unknown to all study participants and assessors.

\section{Procedures}

Subjects were seated erect in a comfortable ergonomic chair in a private room. Subjects wore a nose clip for the entire duration of the study so they could not smell any of the scents from the topical analgesics. Subjects were not allowed to view the application of the topical analgesics and they were not permitted to look at their shoulder during the entire process. Assessor \#1 entered the room and palpated the subject's right shoulder in order to determine the presence and location of an MTrP in the upper trapezius muscle adjacent to the $7^{\text {th }}$ cervical vertebrae and the $1^{\text {st }}$ thoracic vertebrae. This was marked with a black dot. Assessor \#1 exited the room and assessor \#2 entered and performed the baseline testing of the outcome measures (Figure 1). The rangiometer was placed on the subject's head. From a neutral position, right and left active end-range lateral flexion measurements were recorded. The pressure algometer was applied over the marked trapezius trigger 

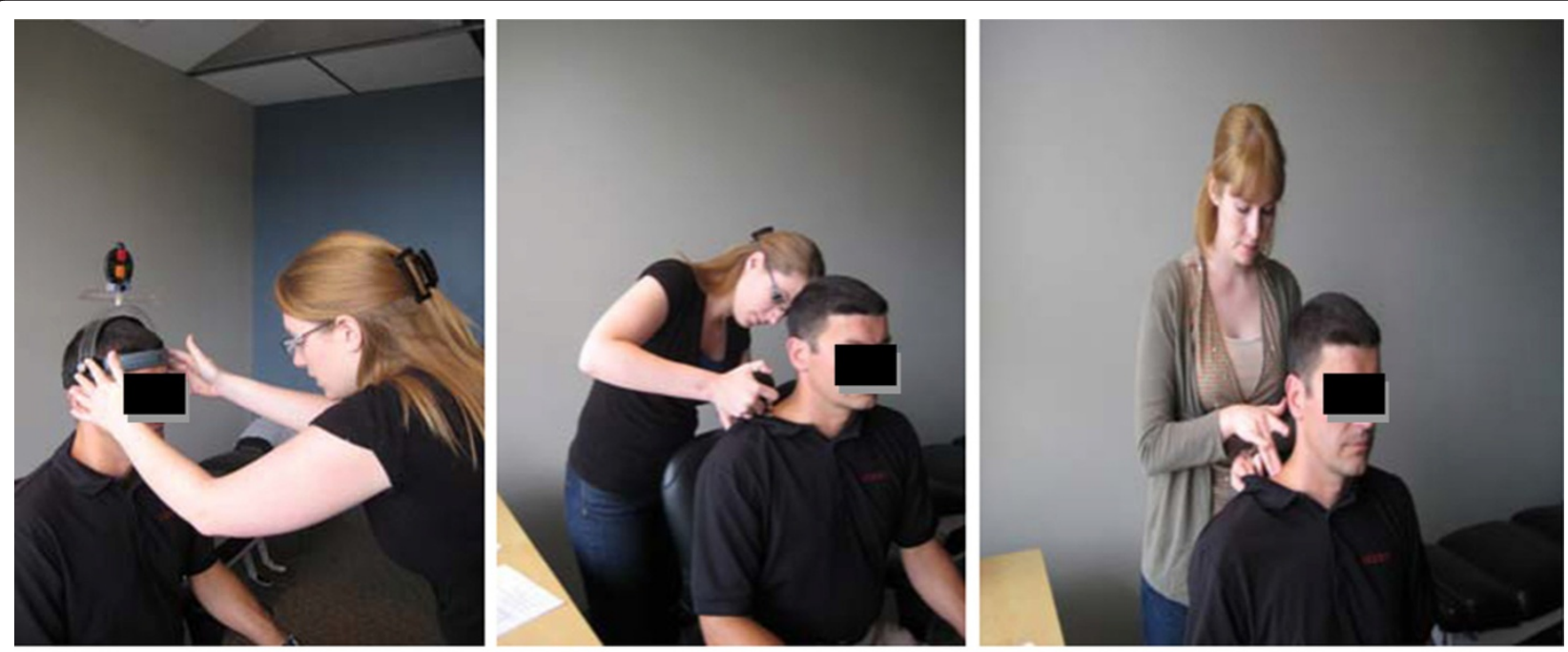

(a) Range of motion, (b) pressure algometry, and (c) topical application.

Figure 1 (a) Range of motion, (b) pressure algometry, and (c) topical application.

point for the baseline pressure reading. The subject was instructed to indicate when the pressure point was painful.

Following the initial outcome measurements, assessor \#1 re-entered the room and applied one of the six samples according to the randomization schedule which was revealed only at that time in the area of the marked pressure point (Figure 1). The subject was instructed to stay seated in the chair with little head movement for five to seven minutes, following which, assessor \#2 reassessed and recorded the pain and range of motion outcome measures. The study was conducted over a 7-day period.

\section{Analyses}

Data were first analyzed descriptively-baseline, postintervention and change scores. Change scores for each of the three measurements (Pressure pain threshold, Right and Left lateral flexion) were analyzed using a 5way ANOVA. Statistically significant ANOVA's ( $p>$ $0.05)$ were then subjected to multiple t-tests with Holm's adjustment of the p-value. As such, the alpha levels were set at 0.007 .

\section{Results}

120 subjects were entered into the study, 20 in each group (63 females; ages 18-80). Fifty-six percent (56\%) of patients presented with clinical shoulder or neck pain. Group demographics and clinical baseline values can be found in Table 1 . There were no significant differences regarding group demographics and clinical baseline values.
The pre- and post-treatment results for pressure threshold are displayed in Table 2. ANOVA for intergroup differences was significant $(F=5.2, p=0.002)$. Significant intra-group increases for BG, PTMC roll-on and MM cream were obtained with an increased threshold of $0.5 \mathrm{~kg} / \mathrm{cm}^{2}(+/-0.15), 0.72 \mathrm{~kg} / \mathrm{cm}^{2}(+/-0.17)$ and $0.47 \mathrm{Kg} / \mathrm{cm}^{2}(+/-0.19)$ respectively.

With respect to the inter-group comparisons, PTMC roll-on showed significant increases in pressure threshold compared with PLA ( $p=0.002)$ and $\mathrm{IH}(\mathrm{p}=0.006)$. In addition, $B G$ demonstrated significant increases in pressure threshold compared with PLA ( $p=0.0003$ ).

The pre- and post-treatment results for right and left lateral flexion did not show significant increases in range of motion for any of the topical analgesics (Table 3).

Patient satisfaction ratings were high in each group and there were no significant differences between groups. There were no adverse reactions or complaints of pain aggravation reported in this study.

\section{Discussion}

This study investigated the immediate effect of six different topical analgesic creams on pressure pain threshold at a single trapezius MTrP and on bilateral cervical lateral flexions. We found that the topical analgesics BG, PTMC roll-on and MM cream demonstrated significant and clinically important increases in pressure threshold when comparing short-term MTrP tenderness. In addition, PTMC roll-on was better than placebo and Icy Hot Extra Strength Cream in reducing short-term MTrP tenderness. BG was better than placebo at reducing short-term MTrP tenderness. 
Table 1 Group demographics and clinical baseline values

\begin{tabular}{|c|c|c|c|c|c|c|c|}
\hline Variable & $\underset{A}{\text { Group }}$ & $\begin{array}{c}\text { Group } \\
\text { B }\end{array}$ & $\underset{\text { Croup }}{\text { Gro }}$ & $\begin{array}{c}\text { Group } \\
\text { D }\end{array}$ & $\begin{array}{c}\text { Group } \\
\mathrm{E}\end{array}$ & $\begin{array}{c}\text { Group } \\
\text { F }\end{array}$ & Statistic \\
\hline AGE & $\begin{array}{c}48.5 \\
(17.7)\end{array}$ & $\begin{array}{c}48.5 \\
(14.7)\end{array}$ & $\begin{array}{l}47.9 \\
(15.1)\end{array}$ & $\begin{array}{c}47.1 \\
(14.7)\end{array}$ & $\begin{array}{c}45.0 \\
(12.5)\end{array}$ & $\begin{array}{l}51.1 \\
(15)\end{array}$ & $\begin{array}{c}N S \\
F=0.3 \\
p=0.89\end{array}$ \\
\hline GENDER & $\begin{array}{l}M=8 \\
F=12\end{array}$ & $\begin{array}{l}M=8 \\
F=12\end{array}$ & $\begin{aligned} M & =11 \\
F & =9\end{aligned}$ & $\begin{aligned} M & =11 \\
F & =9\end{aligned}$ & $\begin{aligned} M & =11 \\
F & =9\end{aligned}$ & $\begin{array}{l}M=7 \\
F=13\end{array}$ & NS CSq $=4.0, p=0.97$ \\
\hline NECK and SHOULDER PAIN & $\begin{array}{c}Y=11 \\
N 9\end{array}$ & $\begin{array}{l}Y=12 \\
N=8\end{array}$ & $\begin{array}{l}Y=11 \\
N=9\end{array}$ & $\begin{array}{l}Y=10 \\
N=10\end{array}$ & $\begin{array}{l}Y=12 \\
N=8\end{array}$ & $\begin{array}{l}Y=11 \\
N=9\end{array}$ & NS CSq $=2.2, p=0.99$ \\
\hline Pressure Pain Threshold $\left(\mathrm{kg} / \mathrm{in}^{2}\right)$ & $\begin{array}{c}4.5 \\
(2.2)\end{array}$ & $\begin{array}{c}4.6 \\
(1.5)\end{array}$ & $\begin{array}{c}4.9 \\
(2.4)\end{array}$ & $\begin{array}{c}4.2 \\
(1.3)\end{array}$ & $\begin{array}{l}4.1 \\
(0.9)\end{array}$ & $\begin{array}{c}4.5 \\
(2.4)\end{array}$ & $\begin{array}{c}\text { NS } \\
F=0.41 \\
p=0.83\end{array}$ \\
\hline
\end{tabular}

None of the groups demonstrated a statistically significantly increase in right or left lateral flexion.

The effectiveness of the topical analgesics that showed clinically significant improvements in cervical spine pressure threshold may be due to several factors. Eucalyptus oil, that was found in the PTMC solution, has been shown to transport active ingredients deep into the subcutaneous tissues $[28,29]$. Camphor and menthol, found in both BG and PTMC, have been proven to provide immediate pain relief $[19,30,31]$. Glucosamine sulfate, chondroitin sulfate, dimethyl sulfoxide and Boswellia serrata extract, found in the PTMC roll-on formulation, have been shown to improve circulation and reduce inflammation, thus reducing pain in the short-term $[19,32,33]$. In addition, magnesium chloride, which is unique to the PTMC roll-on, has been shown to be effectively absorbed through the dermis into muscle $[34,35]$.

Topical analgesics are typically easy to self-apply. While this is a feature of many non-pharmacologic topicals, evidence of the effectiveness of the topical analgesics tested in this study is significantly lacking in the research literature. The results from the study demonstrate promising results for patients with myofascial pain. Since the topical analgesics are easy to use, they may improve the patients' self-care through increased compliance and help alleviate the painful symptoms they experience from MTrPs.

Many clinicians use these topical analgesics during multiple sessions or in combination with other proven therapies. Many clinicians theorize that the combination therapy or multiple session uses will result in long-term benefits. The intervention in this study was applied in one single session with only short-term outcomes measured. A similar study has been published on the outcomes from a single manual therapy session for patients with neck pain [36]. A clinical prediction rule has been formulated for single-session response to manual therapy for neck pain. Our findings show similar benefits compared with the manual therapy neck pain study and provides support for further research. Future studies with multiple sessions over several treatment days or in combination with other therapies are needed to validate the effects of the topical analgesics commonly used in clinical settings.

\section{Limitations}

This study used participants with and without cervical spine and trapezius pain. This may have attenuated the outcomes measured in this study. Future research should separately evaluate pain and non-painful groups to eliminate any confounding factors.

Table 2 Pressure pain thresholds.

\begin{tabular}{clllll}
\hline Group & $\begin{array}{l}\text { Pre-Tx } \\
\left(\mathbf{k g} / \mathbf{c m}^{2}\right)\end{array}$ & $\begin{array}{l}\text { Post-Tx } \\
\left(\mathbf{k g} / \mathbf{c m}^{2}\right)\end{array}$ & $\begin{array}{l}\text { Change } \\
\left(\mathbf{k g} / \mathbf{c m}^{2}\right)\end{array}$ & $\begin{array}{l}\text { Intra-group } \\
\text { Significance }\end{array}$ & $\begin{array}{l}\text { Inter-group } \\
\text { Significance* }\end{array}$ \\
\hline A & $4.5(+/-0.48)$ & $5.0(+/-0.56)$ & $0.5(+/-0.15)$ & $\mathrm{p}=0.002$ & $\mathrm{~A}>\mathrm{C}(\mathrm{p}=0.0003)$ \\
\hline B & $4.6(+/-0.33)$ & $4.5(+/-0.35)$ & $-0.45(.12)$ & $\mathrm{p}=0.37 \mathrm{NS}$ & \\
\hline C & $4.9(+/-0.53)$ & $4.6(+/-0.54)$ & $-0.3(+/-0.19)$ & $\mathrm{p}=0.067 \mathrm{NS}$ & $\mathrm{D}>\mathrm{C}(\mathrm{p}=0.002)$ \\
\hline D & $4.2(+/-0.28)$ & $4.96(+/-0.39)$ & $0.72(+/-0.17)$ & $\mathrm{p}=0.0002$ & $\mathrm{D}>\mathrm{E}=0.006)$ \\
\hline E & $4.1(+/-0.20)$ & $4.4(+/-0.32)$ & $0.35(+/-0.23)$ & $\mathrm{p}=0.07 \mathrm{NS}$ & \\
\hline F & $4.4(+/-0.55)$ & $4.9(+/-0.59)$ & $0.47(+/-0.19)$ & $\mathrm{p}=0.01$ & \\
\hline
\end{tabular}

$\mathrm{A}=$ Bengay Ultra Strength Muscle Pain ointment, $\mathrm{B}=$ Biofreeze roll-on gel, $\mathrm{C}=$ Placebo, D $=$ Professional Therapy Muscle Care roll-on, E $=$ Icy Hot Extra Strength Cream, $\mathrm{F}=$ Motion Medicine

*Bonferroni corrected $p$ value $=0.007$ 
Table 3 Right Lateral Flexion.

\begin{tabular}{cllll}
\hline Group & $\begin{array}{l}\text { Pre-Tx } \\
\text { (Degrees) }\end{array}$ & $\begin{array}{l}\text { Post-Tx } \\
\text { (Degrees) }\end{array}$ & $\begin{array}{l}\text { Change } \\
\text { (Degrees) }\end{array}$ & Significance \\
\hline A & $39.4(+/-3.3)$ & $44.9(+/-2.6)$ & $5.45(+/-1.7)$ & NS \\
\hline B & $45.9(+/-2.3)$ & $46.7(+/-2.9)$ & $8(+/-1.5)$ & NS \\
\hline C & $40.6(+/-2.8)$ & $40.1(+/-2.4)$ & $-0.45(+/-1.1)$ & NS \\
\hline D & $44.4(+/-2.9)$ & $48.3(+/-3.0)$ & $3.95(+/-1.6)$ & NS \\
\hline E & $46.9(+/-2.7)$ & $48.4(+/-2.7)$ & $1.4(+/-1.5)$ & NS \\
\hline F & $44.5(+/-1.7)$ & $44.7(+/-1.6)$ & $0.2(+/-1.1)$ & NS
\end{tabular}

A = Bengay Ultra Strength Muscle Pain ointment, B = Biofreeze roll-on gel, $C$ $=$ Placebo, $\mathrm{D}=$ Professional Therapy Muscle Care roll-on, $\mathrm{E}=$ Icy Hot Extra Strength Cream, $\mathrm{F}=$ Motion Medicine

Subjects were not excluded if they had prior experience, nor, was prior experience measured as an explanatory variable. However, our efforts to blind subjects to the nature of the topicals used should have reduced the effect of any prior treatment experience.

Only one trial of pressure algometery and cervical ranges of motion was obtained pre-post intervention for each patient. As there is likely to be some variability with examiner testing, multiple recordings should be obtained in future studies.

It is unknown if any of the significant results obtained immediately post-intervention would be sustained over a longer period of time. Future studies should measure longer term outcome measures, such as a few hours after treatment.

\section{Conclusions}

This study demonstrated that some topical analgesic products do reduce myofascial pain or tenderness. The results of this study demonstrated that there were clinically important and significant differences between the topical analgesics tested. The BG, MM and the PTMC roll-on ointment demonstrated significant increases in pressure threshold levels. PTMC roll-on and BG were significantly superior to the placebo in the short-term reduction of myofascial tenderness. Furthermore, the PTMC roll-on demonstrated that it was significantly superior to the IH in the short-term reduction of myofascial tenderness.

There were no significant differences in range of motion testing for any of the topical analgesics. Future studies are needed to evaluate the effect of topical analgesics on the duration of effects of topical pain relief.

\section{Endnotes}

${ }^{a}$ Professional Therapy Muscle Care ${ }^{\circledR}$ Extra Strength Pain Relief Roll-on, Muscle Care Products (div. of Active \& Innovative Inc.) Toronto, ON M4T 2V7
${ }^{\mathrm{b}} \mathrm{MM}$ Cream, Motion Medicine Inc., Calgary, AB T2Y $2 \mathrm{Z7}$

${ }^{\mathrm{c} B e n g a y}$ Ultra Strength Muscle Pain non-greasy, nonstaining cream, Johnson \& Johnson Inc. Markham, ON L3R 5L2, Canada.

${ }^{\mathrm{e}}$ Icy Hot Extra Strength Pain Relieving Cream, Chattem Canada, Mississauga, ON L5N 2K7, Canada

${ }^{\mathrm{f}}$ Biofreeze Pain Relieving Roll-on Gel with Ilex, Royal Cross, Concord, ON L4K 2L9, Canada

\section{Acknowledgements}

We thank Roslyn Manchee for her help as project administrator.

\section{Author details}

${ }^{1}$ Toronto, ON, Canada. ${ }^{2}$ Canadian Memorial Chiropractic College, 6100 Leslie Street, Toronto, ON M2H 3J1, Canada. ${ }^{3} 204$ Parkmount, Toronto, ON M4J 4V6, Canada. ${ }^{4}$ Lakeview Chiropractic Health and Wellness, 2B 3602 Taylor St. E, Saskatoon, SK S7H 5H9, Canada. ${ }^{5} 777$ Woodbine Ave, Toronto, ON M4E 2J5, Canada.

\section{Authors' contributions}

DA have made substantial contributions to the acquisition of data, analysis and interpretation of data, have been involved in drafting the manuscript or revising it critically for important intellectual content and have given final approval of the version to be published. $\mathrm{AH}$ and $\mathrm{CH}$ have made substantial contributions to conception and design, acquisition of data, analysis and interpretation of data, have been involved in drafting the manuscript or revising it critically for important intellectual content and have given final approval of the version to be published. HV made substantial contributions to the design of this study as well as to the analyses and interpretations of the findings. He was substantially involved in drafting the manuscript or revising it critically for important intellectual content and has given final approval of the version to be published. All authors read and approved the final manuscript.

\section{Competing interests}

The authors declare that they have no competing interests.

Received: 9 December 2011 Accepted: 21 March 2012

Published: 21 March 2012

\section{References}

1. Skootsky SA, Jaeger B, Oye RK: Prevalence of myofascial pain in general internal medicine practice. West J Med 1989, 151:157-160.

2. Gerwin RD: Classification, epidemiology, and natural history of myofascial pain syndrome. Curr Pain Headache Rep 2001, 5:412-420.

3. Gerwin RD: A review of myofascial pain and fibromyalgia-factors that promote their persistence. Acupunct Med 2005, 23:121-134.

4. Vernon $\mathrm{H}$, Schneider $\mathrm{M}$ : Chiropractic management of myofascial trigger points and myofascial pain syndrome: a systematic review of the literature. J Manipulative Physiol Ther 2009, 32:14-24.

5. Norman HR: Muscle pain syndromes. Am J Phys Med Rehabil 2007, 86: S47-S58.

6. Harden RN, Bruehl SP, Gass S, Niemiec C, Barbick B: Signs and symptoms of the myofascial pain syndrome: a national survey of pain management providers. Clin J Pain 2000, 16:64-72.

7. Travell J, Rinzler SH: The myofascial genesis of pain. Postgrad Med 1952, 11:425-434.

8. Travell J, Simons D: Myofascial Pain and Dysfunction: The Trigger Point Manual Baltimore MD: Williams and Wilkens; 1983.

9. Cummings M, Baldry P: Regional myofascial pain: diagnosis and management. Best Pract Res Clin Rheumatol 2007, 21:367-387.

10. Fernandez de las Penas C, Sohrbeck Campo M, Fernandez Carnero J, Miangolarra Page JC: Manual therapies in myofascial trigger point treatment: a systematic review. J Bodyw Mov Ther 2005, 9:27-34. 
11. Cummings TM, White AR: Needling therapies in the management of myofascial trigger point pain: a systematic review. Arch Phys Med Rehabil 2001, 82:986-992.

12. Harris RE, Clauw DJ: The use of complementary medical therapies in the management of myofascial pain disorders. Curr Pain Headache Rep 2002, 6:370-374.

13. Rickards LD: The effectiveness of non-invasive treatments for active myofascial trigger point pain: a systematic review of the literature. Inter J Osteop Med 2006, 9:120-136.

14. Bronfort G, Haas M, Evans R, Leininger B, Triano J: Effectiveness of manual therapies: the UK evidence report. Chiropr Osteopat 2010, 18:3.

15. Mason L, Moore RA, Edwards JE, Derry S, McQuay HJ: Topical NSAIDs for acute pain: a meta-analysis. BMC Fam Pract 2004, 5:10.

16. Argoff CE: A review of the use of topical analgesics for myofascial pain. Curr Pain Headache Rep 2002, 6:375-378.

17. Matthews P, Derry S, Moore RA, McQuay HJ: Topical rubefacients for acute and chronic pain in adults. Cochrane Database Syst Rev 2009, 8(3): CD007403.

18. Sontakka S, Thawani V, Pimpalkhute S, Kabra P, Babhulkar S, Hingorani L: Open, randomized, controlled clinical trial of Boswellia serrata Extract as compared to Valdecoxib in osteoarthritis of knee. Indian J Pharmacol 2006, 39:27-29.

19. Cohen M, Wolfe R, Mai T, Lewis D: A randomized, double blind, placebo controlled trial of a topical cream containing glucosamine sulfate, chondroitin sulfate, and camphor for osteoarthritis of the knee. J Rheumatol 2003, 30:523-528.

20. Fischer AA: Pressure algometry over normal muscles. Standard values, validity and reproducibility of pressure threshold. Pain 1987, 30:115-126.

21. Piva SR, Erhard RE, Childs JD, Browder DA: Inter-tester reliability of passive intervertebral and active movements of the cervical spine. Man Ther 2006, 11:321-330.

22. Al Shenqiti AM, Oldham JA: Test-retest reliability of myofascial trigger point detection in patients with rotator cuff tendonitis. Clin Rehabil 2005, 19:482-487.

23. Bendtsen $L$, Jensen $R$, Jensen NK, Olesen J: Pressure-controlled palpation: a new technique which increases the reliability of manual palpation. Cephalalgia 1995, 15:205-210.

24. Boline PD, Haas M, Meyer JJ, Kassak K, Nelson C, Keating JC Jr: Interexaminer reliability of eight evaluative dimensions of lumbar segmental abnormality: Part II. J Manip Physiol Ther 1993, 16:363-374

25. Gerwin RD, Shannon S, Hong CZ, Hubbard D, Gevirtz R: Interrater reliability in myofascial trigger point examination. Pain 1997, 69:65-73.

26. Gerwin R, Shannon S: Interexaminer reliability and myofascial trigger points. Arch Phys Med Rehabil 2000, 81:1257-1258.

27. Levoska S, Keinanen-Kiukaanniemi S, Bloigu R: Repeatability of measurement of tenderness in the neck-shoulder region by a dolorimeter and manual palpation. Clin J Pain 1993, 9:229-235.

28. Yamane MA, Williams AC, Barry BW: Terpene penetration enhancers in propylene glycol/water co-solvent systems: effectiveness and mechanism of action. J Pharm Pharmacol 1995, 47:978-989.

29. Narishetty ST, Panchagnula R: Effect of L-menthol and 1,8-cineole on phase behavior and molecular organization of SC lipids and skin permeation of zidovudine. J Control Release 2005, 102:59-70.

30. Patel T, Ishiuji $Y$, Yosipovitch G: Menthol: a refreshing look at this ancient compound. J Am Acad Dermatol 2007, 57:873-878.

31. Cliff MA, Green BG: Sensory irritation and coolness produced by menthol: evidence for selective desensitization of irritation. Physiol Behav 1994, 56:1021-1029.

32. Beilke MA, Collins-Lech C, Sohnle PG: Effects of dimethyl sulfoxide on the oxidative function of human neutrophils. J Lab Clin Med 1987, 110:91-96.

33. Kimmatkar N, Thawani V, Hingorani L, Khiyani R: Efficacy and tolerability of Boswellia serrata extract in treatment of osteoarthritis of knee-a randomized double blind placebo controlled trial. Phytomedicine 2003, 10:3-7.

34. Nagai I, Gebrewold A, Altura BT, Altura BM: Magnesium salts exert direct vasodilator effects on rat cremaster muscle microcirculation. Arch Int Pharmacodyn Ther 1988, 294:194-214.

35. Nishio A, Gebrewold A, Altura BT, Altura BM: Comparative vasodilator effects of magnesium salts on rat mesenteric arterioles and venules. Arch Int Pharmacodyn Ther 1989, 298:139-163.
36. Vernon H, Humphreys BK: Chronic mechanical neck pain in adults treated by manual therapy: a systematic review of change scores in randomized controlled trials of a single session. J Man Manip Ther 2008, 16:E42-E52.

doi:10.1186/2045-709X-20-7

Cite this article as: Avrahami et al:: A randomized, placebo-controlled double-blinded comparative clinical study of five over-the-counter nonpharmacological topical analgesics for myofascial pain: single session findings. Chiropractic \& Manual Therapies 2012 20:7.

\section{Submit your next manuscript to BioMed Central and take full advantage of:}

- Convenient online submission

- Thorough peer review

- No space constraints or color figure charges

- Immediate publication on acceptance

- Inclusion in PubMed, CAS, Scopus and Google Scholar

- Research which is freely available for redistribution

Submit your manuscript at www.biomedcentral.com/submit
Biomed Central 